II Sección: Sociedad, juventud e inmigración

\title{
Discursos filosóficos políticos sobre las personas jóvenes: aproximaciones en la historia
}

\author{
Johanna Arce \\ Ministerio de Cultura y Juventud \\ San José, Costa Rica \\ arce.johanna@gmail.com \\ https://orcid.org/0000-0002-0786-7964
}

Recibido: 11 de agosto de 2017

Aceptado: 2 de enero de 2018

\section{RESUMEN}

El objetivo principal de este análisis busca lograr una aproximación a los discursos que han estado presentes en diferentes momentos de la historia en los cuales se aborda a las personas jóvenes.

La juventud ha sido utilizada como una categoría para segmentar a la población en términos basados principalmente en la edad cronológica, asignándose características y tareas evolutivas que la persona debe cumplir.

Partiendo de la concepción histórica sobre las personas jóvenes, así la sociedad plantea un "proyecto" que engloba las acciones que la sociedad, la familia y la institucionalidad estructuran, con el fin de establecer un recorrido de formación de las personas jóvenes, de cara a la concepción de persona adulta en la que se convertiría a futuro. Dependiendo de la concepción existente sobre las juventudes así será los niveles y mecanismos de participación y exigibilidad de derechos con los que cuente este sector de la población.

Juventud, juventudes, jóvenes, adolescencia son conceptos que han sido utilizados en la historia, presentándose debates en su aplicación literaria, filosófica y análisis psicológico. La identificación de estos discursos rinda elementos para determinar a concepción de persona joven que se maneja en cierto contexto y así poder reconocer cual es la respuesta de la sociedad ante esta población.

PALABRAS CLAVE: Juventudes; adolescencia; subculturas juveniles; identidades; discursos

Political philosophical discourses on young people: approximations in history

\section{(C) $(0 \otimes)$}

La Revista Estudios es editada por la Universidad de Costa Rica y se distribuye bajo una Licencia Creative Commons Atribución-NoComercial-CompartirIgual 3.0 Costa Rica. Para más información envíe un mensaje a 


\section{ABSTRACT}

The main objective of this analysis is to achieve an approximation to the discourses that have been present in different moments of history in which young people are approached.

Youth has been used as a category to segment the population in terms based mainly on chronological age, assigning characteristics and evolutionary tasks that the person must fulfill.

Starting from the historical conception of young people, so the society proposes a "project" that encompasses the actions that society, the family and the institutional structure, in order to establish a path of formation of young people, facing the conception of adult person in which he would become in the future. Depending on the existing conception of the youth, this will be the levels and mechanisms of participation and enforceability of rights that this sector of the population has. Youth, youth, youth, adolescence are concepts that have been used in history, presenting debates in their literary, philosophical and psychological analysis. The identification of these discourses yields elements to determine the conception of a young person that is managed in a certain context and thus be able to recognize what the response of society is to this population.

KEYWORDS: Youth; adolescence; youth subcultures; identities; speeches

\section{INTRODUCCION}

La historia ha partido de concepciones filosóficas que han tratado de dar explicación a la vida o bien explican la naturaleza de los procesos sociales o en otra medida, proponen "el deber ser" de la sociedad.

Se ha propuesto un orden a la sociedad y en ese "orden" se establecen jerarquías que conllevan posiciones sociales. Es muy interesante analizar cómo se visualiza y define "lo que es bueno y lo que es malo", en medio de estas posiciones, evidentemente se hacen análisis que podrían justificar el porqué de las cosas. ¿Por qué las diferencias sociales?

También hay preguntas que han marcado grandes discusiones sobre el ser humano, su naturaleza, su ciclo de vida y cómo vive en sociedad. En este trabajo centra la atención en las personas jóvenes, cómo ha sido conceptualizada esta población, como se visualiza su papel en la sociedad a partir de los análisis que realizan diferentes teóricos.

\section{(c) (†) (-)}

La Revista Estudios es editada por la Universidad de Costa Rica y se distribuye bajo una Licencia Creative Commons Atribución-NoComercial-CompartirIgual 3.0 Costa Rica. Para más información envíe un mensaje a 
El Estado al formular políticas y programas de atención a las personas jóvenes, se basa en marcos conceptuales que reflejan acciones para esta población. Es importante reconocer los discursos políticos sobre las personas jóvenes, de manera que se puedan reconocer realidades y proponer acciones que mejoren la calidad de vida de dicho sector. Con el objetivo de visualizar este sector de la población se propone desde la filosofía política, estudiar cómo se ha enfocado a las personas jóvenes a través de la historia.

"La filosofía política es parte de la política misma. Ahora bien, el discurso filosófico-político, como el discurso ético, tiene una especificidad propia, interna, que lo distingue de otras formas de discurso" (Salas, 2016, p.2). Partiendo de esa especificidad es que se busca comprender la posición de los grandes pensadores, sobre la juventud y contraponerlos con enfoques actuales sobre esta población.

En un primer momento, este trabajo analizará el pensamiento de autores como Aristóteles (1983), Hobbes (1992), Locke (1999) y Rousseau (2003). En una segunda parte se revisan pensadores más contemporáneos como Felipe Ghiardo (2004), Carmen Leccardi y Carles Feixa (2011), Ozziel Nájera y Gladys Ortiz (2012), Dina Krauskopf (2003), Revilla (2001) y George Boeree (1998) entre otros. En un tercer momento se estudiarán aspectos de la legislación costarricense en materia de personas jóvenes y finalmente se proponen algunas conclusiones.

Pensar en personas jóvenes, nos remite a considerar el ciclo vital del ser humano. Debido al desarrollo científico, los humanos en la actualidad tienen una esperanza y calidad de vida superior y más larga. En el pasado, el paso de la pubertad y la entrada a la edad adulta, se realizaba en edades más tempranas, esto por cuanto la madurez de las características sexuales corporales eran sinónimo de que la persona podía iniciar su etapa de reproducción y con ello se consideraba adulto.

Para entender el ciclo vital en muchas sociedades se establecieron edades, para poder diferenciar las etapas en las que se encontraban las personas. Desde los

\section{(c) (i) (2)}

La Revista Estudios es editada por la Universidad de Costa Rica y se distribuye bajo una Licencia Creative Commons Atribución-NoComercial-CompartirIgual 3.0 Costa Rica. Para más información envíe un mensaje a 
Revista Estudios, (36), 2018.

ISSN 1659-3316

Junio 2018-Noviembre 2018

Arce Johanna

Estados se han establecido normativas para conceder deberes y derechos a las personas a partir de la edad. Por ejemplo, el Derecho a votar (ciudadanía política) en Costa Rica es a partir de los 18 años y se puede consumir o comprar licor y cigarrillos hasta los 18 años (mayoría de edad).

¿Qué marca la juventud? ¿Cómo se define la juventud? También surge la cuestión sobre la adolescencia y cómo es vista en la historia.

Un aspecto interesante y señalado por los teóricos es que los términos juventud y adolescencia (Urraco,2007) son de uso reciente en la historia, así que al acercarnos al pensamiento de varios autores se debe tener en cuenta el momento histórico en que escriben para así poder comprender las concepciones y roles que le bridaban a esta población.

\section{El Pensamiento de los clásicos sobre la juventud}

En esta primera parte rescataremos algunos de los elementos filosóficos que Aristóteles (1983) plantea en Libro I, Capítulo 12 de La Política. Aristóteles dice que son tres las partes de la administración doméstica: 1. La del señorío, 2. La paterna, 3. La conyugal. Para Aristóteles (1986) "El que es capaz de proveer con la mente es, naturalmente, señor y el que es capaz de ejecutar con el cuerpo esas previsiones, es súbdito y esclavo por naturaleza" (Aristóteles, 1986, p.3). Así que este filósofo consideraba que las personas tienen posiciones diferentes en la sociedad, de acuerdo a lo que son capaces de realizar.

"El ser vivo consta en primer lugar de alma y cuerpo de los cuáles el alma es por naturaleza el elemento rector y el cuerpo el regido" (Aristóteles,1986 p. 8).

Además, plantea que la autoridad que se ejerce con los hijos es regia, porque el que ha engendrado gobierna por razón y afecto y por su mayoría de edad (Aristóteles, 1986 s. p.). Continúa hablando de que el padre y marido gobierna a su mujer y a sus hijos; pero no con la misma clase de autoridad: sino a la mujer como ciudadano y a los hijos como vasallos. Considera que el varón es el más

\section{(c) (i) (2)}

La Revista Estudios es editada por la Universidad de Costa Rica y se distribuye bajo una Licencia Creative Commons Atribución-NoComercial-Compartirlgual 3.0 Costa Rica. Para más información envíe un mensaje a revistaestudios.eeg@ucr.ac.cr. 
apto para la dirección (salvo excepciones antinaturales); dirige mejor el hombre y el de más edad. Dado que siempre se tendrá la relación Gobernante -Gobernado. Es así que define que el rey debe ser naturalmente distinto de sus súbditos.

Desde su pensamiento Aristóteles (1986) explica que el Principio rector del alma implica que por naturaleza existe un elemento dirigente y otro dirigido y concluye con las siguientes premisas:

- En cuanto al marido, la mujer, los hijos y el padre, la virtud es relacionarse entre sí, seguir el bien y rehuir el mal.

- Hay que educar a los hijos y a las mujeres con vistas al régimen político, porque toda casa tiene importancia para la ciudad.

- Es importante educar a las mujeres, pues son la mitad de la población libre y de los niños proceden los ciudadanos.

Desde la concepción de Aristóteles (1986) la persona joven, es el "estado previo" a ser ciudadano, a tener autoridad y liderar. Esto lo podemos visualizar pues se pone como el "estado ideal" del ser humano: el ser adulto, hombre, con edad mayor, libre.

Desde su discurso Aristóteles plantea que "por naturaleza el hombre es un animal social" y que entre más cercano esté a la Ley y a la Justicia será mejor persona. Por esta razón le da un papel importante a la educación, enfocada en el respeto al régimen político.

En este apartado tomaremos algunos elementos planteados por Thomas Hobbes (1588-1679) sobre la naturaleza humana. El autor asegura que el estado natural del hombre es la guerra, la conducta humana se explica por sus pasiones. Plantea que en el estado natural no hay injusticias, solo pasiones y cuando renunciamos a nuestros beneficios es cuando nace la justicia.

\section{(C) $(\Theta \odot$}

La Revista Estudios es editada por la Universidad de Costa Rica y se distribuye bajo una Licencia Creative Commons Atribución-NoComercial-CompartirIgual 3.0 Costa Rica. Para más información envíe un mensaje a 
Hobbes (1992), distingue entre hombres justos e injustos y plantea que el poder es legítimo cuando se ha consentido; explica que existen tres formas de Estado: la Monarquía, la Aristocracia y la Democracia.

Para Hobbes (1992) el fin del Estado es la seguridad y el fin de los hombres es: el cuidado de su propia conservación, el logro de una vida más armónica; es decir, el deseo de abandonar esa miserable condición de guerra.

"es consecuencia necesaria de las pasiones naturales de los hombres, cuando no existe poder visible que los tenga a raya y los sujete, por temor al castigo, a la realización de sus pactos y a la observancia de las leyes de naturaleza" (Hobbes, 1992 p. 144).

Hobbes (1992) explica que las leyes de naturaleza, como las de justicia, equidad, modestia, piedad y, "la de haz a otros lo que quieras que otros hagan por ti", son, por sí mismas, cuando no existe el temor a un determinado poder que motive su observancia. Para este pensador, las pasiones naturales, inducen a la parcialidad, al orgullo, a la venganza y a cosas semejantes. Para Hobbes (1992) la generación del Estado es el único camino para erigir un poder común, capaz de defenderlos contra la invasión de los extranjeros, contra las injurias ajenas. Por el Estado se confiere todo poder y fortaleza a un hombre o a una asamblea de hombres, los cuales, por pluralidad de votos, pueden reducir sus voluntades a una voluntad.

Hobbes (1992) analiza el poder soberano y lo caracteriza por:

1) la fuerza natural, como cuando un hombre hace que sus hijos y los hijos de sus hijos le estén sometidos, siendo capaz de destruirlos si se niegan a ello.

2) por actos de guerra somete a sus enemigos a su voluntad, concediéndoles la vida a cambio de esa sumisión.

Concluye este autor que cuando los hombres se ponen de acuerdo entre sí, para someterse a algún hombre o asamblea de hombres voluntariamente, con la

La Revista Estudios es editada por la Universidad de Costa Rica y se distribuye bajo una Licencia Creative Commons Atribución-NoComercial-CompartirIgual 3.0 Costa Rica. Para más información envíe un mensaje a revistaestudios.eeg@ucr.ac.cr. 
confianza de ser protegidos por ellos contra todos los demás, es cuando puede hablarse de Estado político.

Al analizar el pensamiento de este autor, se puede comprender que su posición es identificar la naturaleza de competencia entre los seres humanos y que para ordenar las relaciones de poder entre las personas se establecen pactos que buscan la justicia, destacando el "someterse" a una autoridad a fin de ser protegidos. En ese plano, destaca a la "familia", en donde privilegia la posición "del padre" para imponer autoridad.

Desde la posición de Hobbes (1992) la persona joven se ve sometida a la fuerza del padre, quien es el soberano y brinda protección.

A continuación, utilizaremos algunos planteamientos teóricos de Locke (1999) que se encuentran desarrollados en Segundo tratado del Gobierno Civil.

Locke (1999) explica que, al unirse los hombres por primera vez en sociedad, todo el poder de la comunidad reside en la mayoría; esa mayoría puede entonces hacer leyes para esa comunidad y ejecutar esas leyes por medio de oficiales que la mayoría nombra y esta forma de poder es una democracia (Locke, 1999, p. 129). Para Locke (1999) el fin de la sociedad es disfrutar de sus propiedades en paz y seguridad (Loke,1999 s.p), ningún miembro de la sociedad está exento de prestar obediencia al poder legislativo, debe ser considerado como el poder supremo (Loke, 1999 p133). Plantea que la primera Ley Fundamental natural es la preservación de la sociedad y de la persona y la Ley necesita del consentimiento de la sociedad, sobre el cual nadie puede ostentar el poder de hacer leyes, la única excepción es cuando la misma sociedad ha dado su consentimiento.

"Porque nadie puede transferir a otro d más poder del que tiene"(Loke,1999, p.133)

Para Locke (1999) hay en todo Estado un poder natural y responde a lo que todo hombre tiene antes de estar en sociedad que es: "hacer la paz o la guerra”. Así,

\section{(c) (7) (-)}

La Revista Estudios es editada por la Universidad de Costa Rica y se distribuye bajo una Licencia Creative Commons Atribución-NoComercial-CompartirIgual 3.0 Costa Rica. Para más información envíe un mensaje a 
para Locke (1999) la ambición o necesidad de preservar la propiedad, la vida, es lo que lleva a realizar "el pacto" y explica que lo que mueve al hombre es la "razón". Locke (1999) analiza "el poder paternal" y explica que debería llamarse "poder de los padres" dado que el padre como la madre tienen igual derecho sobre los hijos. Plantea que los hijos le deben a los padres respeto y reverencia, deben honrarlos. Los hijos deben sujetarse por igual a sus dos progenitores (Locke, 1999, p. 56).

Para este autor la edad o la virtud pueden dar a los hombres justa precedencia. Dice Locke: "los niños, debo confesarlo, no nacen en ese estado de igualdad, si bien a él están destinados. Sus padres tienen una suerte de gobierno y jurisdicción sobre ellos cuando vienen al mundo" (Locke, 1999 p 58). Afirma que la edad y la razón harán que por fin sean hombres, que decidan libremente por sí mismos. Explica que cuando nacemos somos libres y racionales, pero eso no quiere decir que ejerzamos esas facultades.

Es así que la libertad del hombre se fundamenta en que dicho hombre posee razón que lo capacita para instruirse en la ley y así se rija y pueda conocer sus límites de libertad (Locke, 1999, p. 65). El papel de los padres es cuidar e instruir a sus hijos para que conozcan la Ley, es por ello que los padres gobiernan a los hijos, explica: "Dios les ha dado dosis de ternura para que regulen ese poder".

En resumen, para Locke (1999) la persona joven es visualizada como un ser que nace con virtudes, pero necesita lograr una mayor edad para ejercerlas y se encuentra en un momento en que la instrucción es muy importante y debe conocer la Ley.

A continuación analizaremos los argumentos de Rousseau (1712-1778)) en su obra El Contrato Social (2003), publicado en 1762.

Rouseau (2003) explica:

"El hombre ha nacido libre y sin embargo, vive en todas partes entre cadenas" (Rousseau,2003, p..3), se considera amo, pero sigue siendo esclavo y así, se 
establece un orden social. Este autor explica que "el orden social constituye un derecho sagrado que sirve de base a todos los demás. Sin embargo, este derecho no es un derecho natural: está fundado sobre convenciones" (Rousseau, 2003 p4). Se refiere a establecer acuerdos entre las personas, se ordena cómo funcionará la sociedad. Esto se da precisamente cuando las personas deciden vivir en una comunidad.

"La más antigua de todas las sociedades, y la única natural, es la de la familia; sin embargo, los hijos no permanecen ligados al padre más que durante el tiempo que tienen necesidad de él para su conservación. Tan pronto como esta necesidad cesa, los lazos naturales quedan disueltos. Los hijos exentos de la obediencia que debían al padre y éste relevado de los cuidados que debía a aquéllos, uno y otro entran a gozar de igual independencia. Si continúan unidos, no es ya forzosa y naturalmente, sino voluntariamente; y la familia misma no subsiste más que por convención" (Rousseau, 2003, p.4)

Rosseau (2003) plantea que el primer motivo de unión entre las personas, es el principio de conservación, la búsqueda de la supervivencia. La obediencia de los hijos al padre puede simularse a la obediencia de los ciudadanos ante el Estado, por lo tanto se basa en una convención que plantea que "una parte" reconoce liderazgo en "otro".

"Esta libertad común es consecuencia de la naturaleza humana. Su principal ley es velar por su propia conservación, sus primeros cuidados son los que se debe a su persona. Llegado a la edad de la razón, siendo el único juez de los medios adecuados para conservarse, conviértese por consecuencia en dueño de sí mismo" (Rousseau, 2003, p.4)

Para Rosseau (2003) los niños están en un proceso de aprendizaje, aprenden cómo funciona la autoridad, la sociedad y la ley. Considera este autor que la familia es la encargada de brindar a la persona esta formación.

"La familia es pues, si se quiere, el primer modelo de las sociedades políticas: el jefe es la imagen del padre, el pueblo la de los hijos, y todos, 
habiendo nacido iguales y libres, no enajenan su libertad sino en cambio de su utilidad. Toda la diferencia consiste en que, en la familia, el amor paternal recompensa al padre de los cuidados que prodiga a sus hijos, en tanto que, en el Estado, es el placer del mando el que suple o sustituye este amor que el jefe no siente por sus gobernados" (Rousseau, 2003 p4).

Rosseau (2003) plantea que la libertad solo se sacrifica a cambio de la utilidad, de decir, someterse a otro para conservar su vida. Explica que el más fuerte solo puede serlo para siempre si transforma su fuerza en derecho y la obediencia en deber. En su obra plantea que la fuerza no hace el derecho y la persona no está obligada a obedecer más que a los poderes legítimamente establecidos.

"Aun admitiendo que el hombre pudiera enajenar su libertad, no puede enajenar la de sus hijos, nacidos hombres y libres. Su libertad les pertenece, sin que nadie tenga derecho a disponer de ella. Antes de que estén en la edad de la razón, puede el padre, en su nombre, estipular condiciones para asegurar su conservación y bienestar, pero no darlos irrevocable e incondicionalmente; pues acto tal sería contrario a los fines de la naturaleza y traspasaría el límite de los derechos paternales. Sería, pues, necesario para que un gobierno arbitrario fuese legítimo, que a cada generación el pueblo fuese dueño de admitir o rechazar sus sistemas, y en caso semejante la arbitrariedad dejaría de existir" (Rousseau, 2003, p.8).

Rousseau (2003) privilegia entonces la razón y plantea que las personas jóvenes para obtener libertad deben estar en la "edad de la razón". Para Martínez (2016), Rousseau en el "Emilio", publicado en 1762, establece la educación como mecanismo para formar ciudadanos libres, conscientes de sus derechos y deberes. Afirma que hay periodos de aprendizaje ajustado a las edades y que la mejor manera de enseñar es explicando la historia y tomar como base las realidades (Martínez, 2016,s. p.)

Según Pastor (1986) ${ }^{1}$ Rousseau (2003) en Emilio realiza un programa educativo y organiza los siguientes estadios:

\footnotetext{
${ }^{1}$ Pastor Reina (1986) Papel e imágenes de la juventud en España Medieval. Revista en Educación $N^{\circ}$ 281pag 87-97. p71. Recuperado de

https://books.google.co.cr/books?id=dKxMjTn2NacC\&pg=PA171\&lpg=PA171\&dq=Rousseau++edad+de+la

La Revista Estudios es editada por la Universidad de Costa Rica y se distribuye bajo una Licencia Creative Commons Atribución-NoComercial-Compartirlgual 3.0 Costa Rica. Para más información envíe un mensaje a revistaestudios.eeg@ucr.ac.cr.
} 
Revista Estudios, (36), 2018.

La Edad de la Naturaleza del niño de pecho: de los 0 a los 2 años de edad.

La Edad de la Fuerza: de los 12 a los 15 años de edad.

La Edad de la razón y las pasiones: de los 15 a los 20 años de edad.

La Edad de la cordura y del matrimonio: de los 20 a los 25 años de edad. (Pastor, 1986.p71)

El resultado de un verdadero ciudadano sería el resultado de haber pasado exitosamente por todos los estadios. La "edad de la razón", es a partir del conocimiento de la historia y se da alrededor de los 15 años. Según Ramos (2014), Rousseau, además critica la idea de que los niños son capaces de razonar como un adulto. (Ramos, 2014, p.63). Según Martínez (2016), Rousseau (2003) considera que para tratar al niño se debe tener en cuenta su edad, poniéndolo en su lugar y reteniéndolo en él. Por otra parte, explica Martínez (2016), que para Rousseau (2003) la razón y la memoria no se pueden desarrollar de manera separada, para este autor los niños no son capaces de realizar juicios, pues su memoria solo suma las experiencias de su corta vida.

Rousseau (2003) pone especial atención en cómo se organiza una sociedad, cómo se busca la protección mutua. Entonces introduce el concepto de "contrato social".

"Encontrar una forma de asociación que defienda y proteja con la fuerza común la persona y los bienes de cada asociado, y por la cual cada uno, uniéndose a todos, no obedezca sino a sí mismo y permanezca tan libre como antes." (Rousseau, 2003, p.13).

En síntesis, Rousseau (2003) identifica a las personas jóvenes como seres que están en formación, que están aprendiendo sobre la comunidad, la ley y la historia. A medida que crecen en el conocimiento de la historia, llegan a alcanzar la "edad de la razón" y caracteriza por grupos de diferentes edades, desde jóvenes entre los 12 años, hasta los de 25 años, con el inicio de vida en matrimonio.

+razon\&source=bl\&ots=ejvY3XXJD6\&sig=DcE6HdGchNy2DaKIid_vIxg6uIo\&hl=es-

419\&sa=X\&redir_esc=y\#v=onepage $\& \mathrm{q}=$ Rousseau $\% 20 \% 20 \mathrm{edad} \% 20 \mathrm{de} \% 201 \mathrm{a} \% 20 \mathrm{razon} \& \mathrm{f}=$ false

\section{(cc) (i) 8 (2)}

La Revista Estudios es editada por la Universidad de Costa Rica y se distribuye bajo una Licencia Creative Commons Atribución-NoComercial-CompartirIgual 3.0 Costa Rica. Para más información envíe un mensaje a revistaestudios.eeg@ucr.ac.cr. 
Los pensadores que se han analizado en este apartado han centrado gran parte de su interés en lo fundamental que es la educación para las personas jóvenes, como una forma de prepararlos para la vida en comunidad.

\section{DEL PENSAMIENTO CONTEMPORÁNEO}

A nivel de las ciencias en el mundo contemporáneo se dio un amplio estudio, en busca de la comprensión y caracterización del grupo de población joven. Se introdujeron hipótesis sobre lo que es "ser joven", sus expresiones, forma de agrupamiento, códigos y formas de expresión. Las personas jóvenes se consideraron "un objeto de estudio" y es posible identificar un especial interés por resolver las conductas delictivas, el ocio y hábitos que se presentan en esta población.

A continuación, se exploran algunos de estos análisis y sus principales argumentos.

Felipe Ghiardo (2004) plantea una perspectiva respecto de cómo las juventudes establecen comportamientos y códigos de comunicación. Ghiardo, se basa en Mannheim y su teoría de las "generaciones" y enfatiza en que lo importante no son las generaciones en sí mismas. Plantea que es un proceso biológico inevitable para la mantención de una especie. Este autor agrega a la discusión sobre juventudes el análisis sobre las generaciones y la relación con el principio de "relevo generacional" y debate sobre si las generaciones cambian cada 10, cada 15, cada 25 o 40 años.

Por otra parte, Carmen Leccardi, y Carles Feixa, (2011) citan a Ortega y Gasset (1883-1955) quien argumentaba que las personas nacidas en la misma época comparten la misma "sensibilidad vital", diferente a la generación previa y a la posterior, que define su "misión histórica". Ortega y Gasset elabora un "Método histórico de las generaciones”, que parte de la idea del relevo generacional cada

\section{(c) (i) (2)}

La Revista Estudios es editada por la Universidad de Costa Rica y se distribuye bajo una Licencia Creative Commons Atribución-NoComercial-CompartirIgual 3.0 Costa Rica. Para más información envíe un mensaje a 
quince años. Otra posición es la Karl Mannheim, citado por Ghiardo (2004), quien en 1928 hizo aportes al concepto de generación. Lo enmarca en periodos de 30 años y establece que una generación también se caracteriza, por "acontecimientos generacionales", es decir, hechos históricos que marcaron la niñez y la juventud y que tendrán gran influencia el resto de la vida.

Esta teoría ha sido muy utilizada para caracterizar a la población joven, pero ha topado con algunas críticas, pues se han establecido caracterizaciones de generaciones basadas en contextos históricos y geográficos específicos y en algún momento se han realizado generalizaciones para jóvenes que viven en contextos diferentes.

En Costa Rica, las empresas UNIMER y Kolbi se unieron para realizar el estudio \#GENTICO: la verdad de las generaciones en Costa Rica, publicado en el año 2016. Dicho estudio tenía como objetivo identificar los grupos de generaciones en el país, entender su comportamiento y confrontarlo con las teorías de las generaciones internacionales.

En este estudio plantean que Costa Rica tiene cinco generaciones denominadas de la siguiente forma.

\section{Generación AM.}

Aglutina a las personas nacidas entre 1924-1939 y que hoy en día tienen entre los 77 y 92 años de edad. Explican que integra a la Costa Rica campesina; de familias grandes. En las mismas el hombre era el principal proveedor económico y la autoridad en los hogares. La economía se movía alrededor de la agricultura.

\section{Generación Pregonera.}

Esta generación incluye a las personas nacidas entre 1940-1960 y que hoy en día tienen entre los 56 y 76 años de edad. Este grupo contribuyó a la construcción de las bases sociales, fueron parte del proceso de consolidación

\section{(c) (i) (2)}

La Revista Estudios es editada por la Universidad de Costa Rica y se distribuye bajo una Licencia Creative Commons Atribución-NoComercial-CompartirIgual 3.0 Costa Rica. Para más información envíe un mensaje a revistaestudios.eeg@ucr.ac.cr. 
de la democracia y de la creación instituciones públicas del país. Este grupo creció con el bipartidismo político y fue la generación que accedió a la educación en mayor número.

\section{Generación Satelital.}

Este grupo contempla a las personas nacidas entre 1961-1981 y que hoy en día tienen entre los 35 y 55 años de edad. Este grupo vivió la exposición a la televisión: la información, la comunicación y la transmisión del conocimiento giran alrededor de este medio.

\section{Generación Digital.}

Este grupo corresponde a las personas nacidas entre 1982-1999 y que hoy en día tienen entre los 17 y 34 años de edad. Este grupo vive el cambio tecnológico con la llegada de la computadora, el Internet y la telefonía celular.

\section{Generación Virtual.}

Contempla las personas nacidas a partir del año 2000 y que hoy en día tienen 16 años o menos. Es un grupo que está en formación, está construyendo opinión. Desde su nacimiento han estado expuestos a los dispositivos electrónicos, las Redes Sociales y los videojuegos, además son los que más practican actividad física frecuente y se muestran muy tolerantes a temas relacionados con la diversidad de género.

UNIMER (2016) explica que una de las principales conclusiones del estudio plantea que la teoría de las generaciones a nivel internacional no coincide con la situación de los costarricenses, pues los eventos que marcaron a las generaciones son diferentes o bien se presentaron en momentos distintos.

Otra de las conclusiones de dicho estudio es que en Costa Rica no existe generación Millennials tal y como se describe en las teorías internacionales, dado que algunas de sus características podrían ser compartidas por aquellos ubicados en la Generación Digital y en la Generación Virtual, como lo es la cercanía con la tecnología o el interés por el ambiente. Para el caso de las generaciones

\section{(c) (i) (2)}

La Revista Estudios es editada por la Universidad de Costa Rica y se distribuye bajo una Licencia Creative Commons Atribución-NoComercial-CompartirIgual 3.0 Costa Rica. Para más información envíe un mensaje a 
costarricenses se muestran más interesadas en la estabilidad hogareña y laboral, que los Millennials según la teoría internacional mencionada.

En este estudio se concluye que no se pueden establecer características generacionales mundiales o regionales, dado que los eventos que viven las personas y que les marcan como generación son diferentes.

Por otra parte, Nájera y Ortiz (2012) citan al sociólogo Talcott Parsons (1942), quien utilizó el término "cultura juvenil", para referirse a las agrupaciones de jóvenes con rasgos distintivos en la historia, se dirigió a jóvenes de liceos y escuelas secundarias.

Nájera y Ortiz (2012) citan también a John Clarke y Stuart Hall (2000) quienes plantean que:

"las subculturas juveniles no son culturas juveniles, como comúnmente se les denomina, pues en un sentido estricto son ramificaciones de la clase social en la que se ubican, son un apéndice de la cultura parental más amplia, por esto, al estudiar a las subculturas juveniles se deben relacionar con las culturas parentales de las que son sólo un subconjunto. Al mismo tiempo, es importante también situar a las subculturas juveniles dentro del marco más amplio de la cultura dominante, es decir, si estas subculturas juveniles provienen de la clase trabajadora tendrán una relación de subordinación con respecto a la cultura de las clases medias o burguesas" (Clarke, 2000, p. 13).

Estas mismas autoras citan a Valenzuela (2009, p. 40) quien habla de las "identidades juveniles" haciendo referencia a grupos juveniles; para este autor el grupo se caracteriza por tener una estructura en la cual participan diferentes conformaciones de poderes y liderazgos.

Nájera y Ortiz (2012) al retomar a Clarke y Hall (2000), hablan de que en la sociedad existe una "cultura dominante" y que las demás expresiones son denominadas "subculturas", lo que hace que se establezca un posicionamiento de superioridad jerárquica, que podría evidenciar manejos del poder en la sociedad.

\section{(c) (i) (2)}

La Revista Estudios es editada por la Universidad de Costa Rica y se distribuye bajo una Licencia Creative Commons Atribución-NoComercial-CompartirIgual 3.0 Costa Rica. Para más información envíe un mensaje a revistaestudios.eeg@ucr.ac.cr. 
La perspectiva de los autores que se han presentado, se enfoca más en el discurso y análisis de esta población en términos sociológicos y antropológicos. A continuación, se retoman algunos autores que enfocan su análisis desde un punto de vista psicológico.

Dina Krauskopf (2000), analiza la personalidad de las personas adolescentes y como el "adultocentrismo" puede limitar su desarrollo. Esta autora plantea que los proyectos de participación adolescente se constituyen positivamente al modelo de desarrollo que reconoce el aporte de las personas jóvenes, el compromiso de la sociedad civil y la responsabilidad del Estado. La participación real se expresa cuando las personas adolescentes y jóvenes aportan en los procesos. Para esta autora, el objetivo de la sociedad debe ser tomar en cuenta las diversas situaciones de exclusión y apartarse del "adultocentrismo".

Para Duarte (2006) citado por el Consejo de la Persona Joven (2010),

"el adultocentrismo es poner en condición de superioridad a unas personas sobre otras, solo por el hecho de tener cierta edad, ser mayores o cumplir con ciertos roles como lo es trabajar, estar casado, participar en elecciones" (Consejo Persona Joven, 2010, s.p.).

Erick Erickson citado por C. George Boeree (1998), plantea que las personas tienen tareas evolutivas, que deben ir cumpliendo de acuerdo a su edad. Explica que las personas con edades entre los doce y los veinte años se encuentran en la quinta etapa llamada Etapa Identidad versus Confusión de Roles y la tarea central es el desarrollo de la persona y lograr consolidar la identidad.

La sexta etapa se llama Intimidad versus Aislamiento, se extiende desde los veinte años a los cuarenta años, la persona entra a formar parte de la sociedad al desempeñar un trabajo, formar una vida en pareja y tener una familia.

Es importante comprender cuáles son las tareas evolutivas de las personas jóvenes, para entender cuáles son sus necesidades y procurar desde las

La Revista Estudios es editada por la Universidad de Costa Rica y se distribuye bajo una Licencia Creative Commons Atribución-NoComercial-CompartirIgual 3.0 Costa Rica. Para más información envíe un mensaje a 
propuestas de las instituciones, contribuir positivamente al logro pleno de las mismas.

A nivel internacional Naciones Unidas decretó el Primer Año Internacional de la Juventud en 1985, a partir de esa fecha se puso en la agenda de los organismos internacionales, promover acciones para discutir sobre este grupo población y se aprobó la Convención Iberoamericana de Derechos de la Juventud en el año 2008.

Estos acontecimientos promovieron que la temática de la Juventud, se posicionara en la Agenda Gubernamental, impulsada por organismos internacionales como la Organización Iberoamericana de la Juventud (OIJ) y el Fondo de Población de Naciones Unidas (UNFPA). Es interesante que se promoviera el establecimiento de organismos nacionales para la Juventud en los países de la región, pero no existe consenso respecto a las edades que comprende a las personas jóvenes.

A continuación se verá alguna la información para el caso de Costa Rica.

\section{Enfoque institucional}

La legislación costarricense incluye a la población joven del país en la Ley General de la Persona Joven (Ley 8361) y especifica que los jóvenes son aquellos que tienen entre 12 y 35 años de edad. Según los datos del Censo 2011, representan el $42.3 \%$ de la población total del país. La ley se refiere a adolescentes, con edades entre los 12 y 17 años, los jóvenes que son el grupo con edades entre los 18 y 24 años y los jóvenes adultos con edades entre los 25 a los 35 años.

El Consejo de la Persona Joven promueve el Enfoque de Juventudes, como una forma de visualizar a las personas jóvenes, reconociendo el potencial que tienen, definiéndoles como "actores estratégicos del desarrollo".

\section{(c) (1)(2)}

La Revista Estudios es editada por la Universidad de Costa Rica y se distribuye bajo una Licencia Creative Commons Atribución-NoComercial-CompartirIgual 3.0 Costa Rica. Para más información envíe un mensaje a 
"el Enfoque de Juventudes, es una propuesta de trabajo, pero también una posición ideológica, que pretende trascender los discursos de una sociedad que reproduce los estigmas, los prejuicios, el abuso de poder de los grupos mayoritarios hacia los demás grupos sociales, que en el caso de juventudes, se expresa con frecuencia en el adultocentrismo y adultismo" (Consejo de la Persona Joven. 2010).

Desde la institucionalidad en Juventud se promueve la inclusión de este enfoque en la concepción de programas, proyectos y políticas públicas que atañen a esta población.

En los párrafos anteriores se ha realizado una recopilación sobre el pensamiento de algunos filósofos que visualizaron la sociedad, la familia, los roles entre hombres y mujeres y también de las personas jóvenes. Por otra parte, se mencionaron las posiciones de pensadores más contemporáneos y reprodujimos sus conceptos como, adolescencia, juventud y generación; dándose un énfasis en las características de las generaciones como forma de relevo generacional en la sociedad.

Por otra parte, se planteó el concepto de "subcultura juvenil" para evidenciar y entender las diferencias entre una "cultura general o dominante" y las agrupaciones de jóvenes que expresan códigos que les destacan y a la vez les marginan de la "cultura dominante".

A la discusión se suma, el concepto de "adultocentrismo" para explicar como una sociedad privilegia la condición de una persona sobre otra, basándose en su edad, conocimiento, posición o roles. Se observó como en el pensamiento clásico, se visualiza a la persona joven como sujeto en formación, en una etapa en que debe comprender la ley, las normas sociales, la historia, que le dan los elementos para convertirse en un adulto.

\section{(c) $($ ) (2) (2)}

La Revista Estudios es editada por la Universidad de Costa Rica y se distribuye bajo una Licencia Creative Commons Atribución-NoComercial-CompartirIgual 3.0 Costa Rica. Para más información envíe un mensaje a 
Por otra parte, en el pensamiento contemporáneo, encontramos el interés por leer y comprender las formas de "resistencia" por parte de las juventudes hacia una "cultura dominante". Se hace evidente el interés por caracterizar identidades de agrupaciones de jóvenes. Actualmente se introduce el análisis desde las teorías psicológicas, como una forma de comprender este periodo de vida desde las crisis de desarrollo evolutivo, de conflictos internos ante la aparición de la pubertad y la adolescencia como parte del ciclo vital. Sumado a estas lecturas sociológicas, antropológicas y psicológicas se encuentra el enfoque de la institucionalidad gubernamental. El Enfoque institucional para el caso de Costa Rica, propone a las personas jóvenes como sujeto de derechos y como actores estratégicos de desarrollo y establece espacios formales para la participación.

Luego de realizar este vistazo general de lo que diferentes pensadores han visualizado sobre las juventudes, es posible identificar que en la sociedad se presentan diversos discursos sobre este sector de la población. Uno de los autores que realiza un análisis de estos discursos es Revilla (2001) en su artículo "La construcción discursiva de la juventud: de lo general a lo particular". Parte de la definición sobre discursos de Parker (1992, p.10) que dice:

"...discursos son recursos sociales susceptibles de ser utilizados en cualquier argumentación o discusión de carácter científico, y pueden convertirse en recursos utilizables por cualquier miembro de la cultura en la medida en que se difundan y sean conocidos por la población" (Revilla, 2001 p. 105).

Partiendo de esa definición Revilla (2001) identifica los siguientes discursos sobre la juventud.

1. Construcción histórico-social de la juventud: se parte de la idea que la adolescencia es un constructo de la sociedad occidental moderna. Se basa en números estudios en los que retoman aspectos de la historia y como eran visualizados los jóvenes y se destaca que la juventud es vivida de

\section{(c) (i) (2) (2)}

La Revista Estudios es editada por la Universidad de Costa Rica y se distribuye bajo una Licencia Creative Commons Atribución-NoComercial-Compartirlgual 3.0 Costa Rica. Para más información envíe un mensaje a 
acuerdo al momento histórico y de la sociedad en la que la persona se desarrolle.

2. Mitificación de la juvenil: es el colocar lo juvenil en el centro y se exalta en la publicidad como una condición ideal que termina con la adultez. En numerosas ocasiones se rescatan lo vigoroso, fuerte, bello con la condición de ser joven y así las personas jóvenes pueden creer que están en un momento privilegiado de la vida. Los adultos o adultos mayores tratan de reproducir códigos, actitudes del mundo joven y se exalta el "espíritu joven", como una condición deseable.

3. El hedonismo narcisista: se visualiza al joven sin responsabilidades, en una etapa de crecimiento; es una crítica a la juventud. Resalta que en este discurso se pueden observar tres aristas: a) la juventud hedonista que sobrevalora el placer, la juventud como conformista es decir no le interesa insertarse en lo político o en la transformación social y la juventud con tendencia a la privatización, es decir le interesa más lo privado que lo social.

4. Juventud como agente de cambio social: pone a los jóvenes como responsables de innovar, no son responsables por lo que "los adultos han hecho", son críticos de la realidad y son un relevo generacional.

5. La contestación juvenil: plantea que los jóvenes tienen valores distintos a de los adultos, que son críticos y se rebelan contra el orden establecido. Se plantea que cuestionan las instituciones, cuestionan el orden establecido y buscan no ser parte de ese orden. Este discurso asigna a las personas jóvenes una responsabilidad que es mejorar aquello que los adultos han hecho mal y esto también les hace depositarios de que es su responsabilidad cambiar para bien la sociedad.

6. La subcultura juvenil: explica que este discurso tiene su origen en la literatura científica de la Escuela de Chicago. Se enfatizó en que son un grupo con conductas delictivas y agresivas. Por su parte, la Escuela de 
Birmingham se especializó en el estudio de "subculturas juveniles", como aquellos grupos de jóvenes con gustos, modas, intereses específicos y diferentes a la cultura dominante. En estos estudios sobresalen conceptos como "subculturas", "tribus urbanas" y "estilos juveniles".

7. Grupo subordinado y discriminado: se enfatiza en las relaciones de poder en la que se visualiza al sector joven bajo el poder de los adultos. Este discurso plantea el autor, es cuestionado pues atenta contra la subordinación filial, es decir, la relación padres-hijos y al manejo de la autoridad y la disciplina.

8. Búsqueda de Identidad: plantea Revilla (2001) que desde este discurso se ve a la juventud como el periodo de búsqueda y consolidación de identidad su principal exponente es Erickson (1962).

9. Diversidad juvenil: plantea que hay una gran variedad de realidades juveniles, engloba las concepciones de jóvenes innovadores. La diversidad se da por situación económica, intereses y en las trayectorias a la vida adulta.

10. Transición a la vida adulta: este discurso plantea la juventud como un periodo preparatorio para ser adulto, como un proyecto del ser adulto. En este discurso el autor afirma que se pone énfasis en que el joven se inserte exitosamente al mundo laboral y establezca una familia, así que las acciones de la sociedad se encaminan a lograr ese "proyecto de adulto". Para Revilla (2001) este discurso se basa en una "normalización" de la transición a la vida adulta y deja de lado las especificidades entre hombres y mujeres, diversidad sexual y realidades socioculturales.

Revilla (2001) en síntesis plantea lo siguiente:

La juventud está subordinada a los adultos con los que interactúa. La subordinación es un elemento de control que se materializa en ideas negativas de las personas jóvenes como seres conformistas e irresponsables. La sociedad 
visualiza a las personas jóvenes en sus dimensiones como estudiantes y trabajadores, estableciendo así un canon normativo, que deja de lado la diversidad de trayectorias que se presentan, este mismo enfoque no visualiza las diferencias de género. Por otra parte, la edad se constituye en un elemento de categorización de la juventud y la identidad no debe tomarse como algo estático o acabado.

En su análisis de las subculturas juveniles, establece que brindan códigos significantes que aportan a las identidades y expresiones juveniles. Señala que el estilo puede ser adoptado en parte o totalmente por una persona joven. La juventud por sí misma no es innovadora, esa es tarea de los creadores. La juventud acepta el presente y está más cercana a la novedad e innovación. Considera que no se puede tomar a toda la juventud como "agente cambio" o "sujeto histórico", puesto que todos tienen el mismo protagonismo (Revilla, 2001, pp 118-120).

\section{CONCLUSIONES}

En el pensamiento filosófico político de los clásicos como Aristóteles los niños, adolescentes y jóvenes se visualizaban como seres que estaban bajo la tutela soberana del hombre en el marco del gobierno doméstico. Desde este punto de vista el padre tiene sobre el niño y joven la autoridad que le da la edad y su posición de padre.

En el pensamiento de Hobbes (1992) la persona joven se ve sometida a la fuerza del padre. Para Locke (1999) el joven debe respeto y reverencia al "poder paternal", que considera, debería llamarse "poder de los padres" ya que el padre y la madre tienen el mismo derecho sobre los hijos. Los hijos deben sujetarse por igual a sus dos progenitores. Rousseau (2003), por su parte privilegia en su

\section{(c) (i) (2)}

La Revista Estudios es editada por la Universidad de Costa Rica y se distribuye bajo una Licencia Creative Commons Atribución-NoComercial-CompartirIgual 3.0 Costa Rica. Para más información envíe un mensaje a 
pensamiento la razón y plantea que las personas jóvenes para tener libertad deben estar en la "edad de la razón", la cual inicia a los quince años.

En la época más contemporánea como se vio, trabajó en la teoría sobre las generaciones, ubicando a las personas jóvenes en grupos según el momento de su nacimiento y vivencias de la adolescencia y juventud que se marcan con momentos históricos, gustos, modas y eventos que crean identidades y afinidades de generación.

La adolescencia, como concepto se desarrolla más en la época moderna y se caracteriza por los cambios físicos y psíquicos. Se considera una etapa de desarrollo, que requiere de oportunidades para que la persona se conozca a sí misma y logre identificar sus intereses vocacionales.

La juventud como concepto ha evolucionado, desde concebirse como un estado previo a la adultez, a ser analizada como una etapa del ciclo vital, en el cual las personas pueden aportar al desarrollo de las sociedades en su presente. Se ha recalcado en que las personas jóvenes tienen necesidades, derechos y deberes en su momento actual y que su potencial de aporte a la sociedad no se ha aprovechado.

Las generaciones han sido catalogadas como grupos de personas que al nacer en cierta época, comparten un nivel de identificación que las diferencia de otros grupos poblacionales y están marcadas por hechos históricos que les hace tener una identidad específica. Esos hechos varían en cada sociedad, así que es muy ambicioso establecer categorías mundiales de generaciones, por las especificidades históricas, culturales y de acceso a la tecnología de cada sociedad.

\section{(C) $(\Theta \odot$}

La Revista Estudios es editada por la Universidad de Costa Rica y se distribuye bajo una Licencia Creative Commons Atribución-NoComercial-CompartirIgual 3.0 Costa Rica. Para más información envíe un mensaje a 
En el momento actual la juventud en Costa Rica, está protegida por un marco legal. Son jóvenes aquellas personas que tienen entre 12 y 35 años de edad, según la ley 8261 (Ley de la Persona Joven). Este grupo aglutina adolescentes, jóvenes y jóvenes adultos, la Política Pública de la Persona Joven considera estos grupos poblacionales para priorizar sus acciones.

Es posible identificar discursos filosóficos-políticos, psicológicos, antropológicos, sociológicos y algunos construidos culturalmente, sobre las juventudes, concepciones que tratan de caracterizar y categorizar a esta población. Es importante identificarlos para hacer lecturas correctas de cuál es el punto de partida de las propuestas en programas y proyectos dirigidos a dicha población, para poder identificar "ideas preconcebidas" y "estereotipos" que puedan dañar o "estigmatizar" a las personas jóvenes. El reconocer el planteamiento de las juventudes como una población con necesidades, potencialidades, aspiraciones y sujetos de derecho, en su momento presente, es un punto de partida para la búsqueda del diálogo intergeneracional y apertura de espacios de participación.

\section{BIBLIOGRAFÍA}

Aristóteles (1983) La Política. Madrid: Centro de Estudios Constitucionales Bourdieu, Pierre (1990) La juventud no es más que una palabra, en Sociología y Cultura, Grijalbo, México. Recuperado de https://periferiaactiva.files.wordpress.com/2016/03/bourdieu-la-juventud-no-esmc3a1s-que-una-palabra.pdf

Caja Costarricense de Seguro Social (2002). Módulo Socioeducativo para el fortalecimiento de conductas protectoras y la prevención de conductas de riesgos en los y las adolescentes. Costa Rica.

Consejo de la Persona Joven (2003) Política Pública de la Persona Joven. Recuperado de http://www.cpj.go.cr/es/pol\%C3\%ADticas-p\%C3\%BAblicas-y-plande-acci\%C3\%B3n.php

\section{(c) (i) (2)}

La Revista Estudios es editada por la Universidad de Costa Rica y se distribuye bajo una Licencia Creative Commons Atribución-NoComercial-CompartirIgual 3.0 Costa Rica. Para más información envíe un mensaje a 
Consejo de la Persona Joven (2010) El Enfoque de Juventudes Costa Rica: hacia una visibilización positiva de las personas jóvenes: San José: UNFPA

Costa Rica. Asamblea Legislativa (2002) Ley General de la Persona Joven № 8261 y sus reformas.

Costa Rica. Consejo de la Persona Joven (2008) Informe Integrado Primer Encuesta Nacional de Juventudes. San José: GRAFOS

Ghiardo, Felipe (2004) Generaciones y juventud: una relectura de Mannheim y Ortega y Gasset. Ultima Década, núm. 20, 2004, pp. 11-46, Centro de Estudios Sociales: Chile.

Hobbes Thomas (1992) Leviatán. Madrid: Alianza Editorial.

Martinez, Enrique ( 2016) Jean-Jacques Rousseau. Recuperado de http://www.uhu.es/cine.educacion/figuraspedagogia/0_juan_jacobo_rousseau.htm

Krauskopf, Dina (2000) El desarrollo psicológico del adolescente. San José: EUNED.

Krauskopf, Dina (2003) Participación social y desarrollo en la adolescencia / 3a. ed. -- San José: Fondo de Población de las Naciones Unidas.

Leccardi, Carmen, \& Feixa, Carles. (2011). El concepto de generación en las teorías sobre la juventud. Ultima década, 19(34), 11-32. Recuperado en 15 de febrero de 2014, de http://www.scielo.cl/scielo.php?script=sci_arttext\&pid=S0718$22362011000100002 \&$ Ing=es\&tlng=es. 10.4067/S0718-22362011000100002.

Lexicón (2006) Consejo Pontifico para la Familia . Ediciones Palabra :

Madrid.Recuperado de https://books.google.co.cr/books?id=tZ7VreOXuUEC\&pg=PA429\&lpg=PA429\&dq= $\%$ E2\%80\%9Cquien+no+conoce+la+historia,+est\%C3\%A1+condenado+a+repetirla \%E2\%80\%9D.\&source=bl\&ots=S3VI1SFy0N\&sig=OduoR1dQdcGdYPOO4zP9iO1 atZU\&hl=en\&sa=X\&redir esc=y\#v=0nepage\&q=\%E2\%80\%9Cquien $\% 20$ no $\% 20 \mathrm{co}$ noce \%20la\%20historia\%2C\%20est\%C3\%A1\%20condenado\%20a\%20repetirla\%E 2\%80\%9D.\&f=false

Locke John (1999) Segundo tratado sobre el gobierno civil. Biblioteca Nueva, Madrid.

\section{(c) (i) (2)}

La Revista Estudios es editada por la Universidad de Costa Rica y se distribuye bajo una Licencia Creative Commons Atribución-NoComercial-CompartirIgual 3.0 Costa Rica. Para más información envíe un mensaje a revistaestudios.eeg@ucr.ac.cr. 
Margullis Mario (2008) La juventud es más que una palabra. Ensayos sobre cultura y juventud. Editorial Biblos Sociedad: Buenos Aires. Recuperado de http://pdfsr.com/isbn/9789507861130

Martínez Enrique ( 2016)Jean-Jacques Rousseau. Recuperado de http://www.uhu.es/cine.educacion/figuraspedagogia/0 juan jacobo rousseau.htm

Nájera Ozziel y Ortiz Gladys (2012) Identidades juveniles de principios del siglo XXI: los Mireyes. Revista Antropología Experimental $\mathrm{N}^{\circ} 12$, recuperado en http: //revista.ujaen.es/rae

Pastor Reina (1986) Papel e imágenes de la juventud en España Medieval. Revista en Educación №281pag 87-97. p71. Recuperado de https://books.google.co.cr/books?id=dKxMjTn2NacC\&pg=PA171\&lpg=PA171\&dq= Rousseau++edad+de+la+razon\&source=bl\&ots=ejvY3XXJD6\&sig=DcE6HdGchNy 2DaKlid vlxg6ulo\&hl=es-

419\&sa=X\&redir esc=y\#v=onepage\&q=Rousseau\%20\%20edad\%20de\%20la\%20r azon\&f=false

Portal educativo (2014) Concepto de identidad, recuperado en http://concepto.de/concepto-de-identidad/

Ramos, Lago (2014) Rousseau y el ser del hombre. Ediciones Universidad de Salamanca. Recuperado de https://books.google.co.cr/books?id=4MnIBgAAQBAJ\&pg=PA63\&lpg=PA63\&dq=R ousseau++edad+de+la+razon\&source $=$ bl\&ots=pODaS3Yb6M\&sig=EJ9SpZkP9JV 8DEeP-OOz-w29woY\&hl=es-

419\&sa=X\&redir esc=y\#v=onepage\&q=Rousseau\%20\%20edad\%20de\%20la\%20r azon\&f=false

Revilla (2001) La construcción discursiva de la juventud: lo general y lo particular. Universidad Complutense de Madrid, pp 103-122. Recuperado http://www.raco.cat/index.php/papers/article/viewFile/25610/25444

Rousseau Jean Jacques (2003) El Contrato Social. Cásicos de bolsillo. Longseller. Recuperado de www.elaleph.com

Salas, Mario (2016). Programa PF-0807 Seminario Poder y Procesos Socioculturales, Universidad de Costa Rica: Material mimeógrafo.p. 2 
UNIMER (2016) \#GENTICO. La verdad sobre las generaciones en Costa Rica. Recuperado de https://blog.unimercentroamerica.com/costa-rica-cuenta-con-supropio-estudio-de-generaciones.

Urraco, Mariano (2007) "La sociología de la juventud revisitada. De discursos, estudios, e "historias" sobre los "jóvenes"”. Intersticios. Revista Sociológica Pensamiento Crítico Vol. 1. Recuperado de http://www.intersticios.es 